\title{
Working Tool for Robotic Soil Sampling System
}

\author{
Alexey A. LEONOV ${ }^{1^{*}}$ and Olga V. SANKINA ${ }^{1}$ \\ ${ }^{1}$ Kuzbass State Agricultural Academy, Kemerovo, Russian Federation \\ *Correspondence: tmrm@ksai.ru
}

\begin{abstract}
The rationale for the use of robotic complexes of soil sampling for agrochemical analysis and development of the design of the working tool for such a complex is given in this article. The importance of soil agrochemical analysis use to preserve the fertility during agricultural production is proven. The existing complexes for soil sampling are considered. Their advantages and disadvantages are highlighted in the article. The rationale for the use of robotic soil sampling systems has been made. Various technical means for transporting an automatic sampler to a sampling site are considered. Recommendations for choosing a carrier platform are given. The scheme, design and working principle of the working tool for the robotic complex for sampling the soil and the buried unit are presented. Recommendations on the use of autonomous driving programs for robotic systems are given. It is possible to conclude that the developed working tool for the robotic complex of soil sampling, mounted on a robotic platform using autonomous control systems, will make it possible to collect soil samples in an automatic mode. This will significantly reduce the time and energy consumption for performing agrochemical control, as well as increase level of automation.
\end{abstract}

Keywords: soil sampling, robotic complex, working tool, agrochemical examination, fertility.

\section{Introduction}

Life is closely connected with the fertility of the soil cover of the Earth. One of the founders of agrochemistry Y. Libikh said: "In order to preserve the fertility of the soil, it is necessary to return to it everything that is carried out from the field with the yield. Therefore, countries that are not provided with conditions that determine soil fertility cease to exist, according to the law of nature. Those countries that support these conditions ensure themselves a long-term existence, wealth and power". The growth of the planet's population and the number of starving and malnourished people, changes in diet and, consequently, an increase in food demand, required a significant intensification of agricultural production. In this regard, most of the civilized countries of the World pay special attention to the development of highly productive agriculture, problems of reproduction of soil fertility and providing the population with high-quality food [1, p.1].

The development of domestic agriculture is accompanied by a significant intensification of the load on the soil. This inevitably leads to the depletion of land resources and degradation of soil cover in the absence of appropriate environmentally acceptable agricultural technologies. The answer to this challenge was the introduction of sustainable agriculture and precision agriculture technologies to bring agricultural 
practices in line with the ecological state of each plot of the agricultural field. New agricultural technologies require consideration of spatial heterogeneity of soil characteristics. One of the most important soil characteristics is the availability of plants with accessible forms of nutrients [2, p. 29].

Targeted impact on the soil due to its optimal cultivation, the application of organic and mineral fertilizers, liming, phosphorization in scientifically sound doses forms artificial fertility, which is measured in the aggregate by the size of the crop yield [3, p. 68].

In field farming, the soil characteristics of the fields (particle size distribution, acidity, mobile forms of phosphorus and potassium, organic matter, density, moisture content, etc.) are crucial for calculating the doses of fertilizers for a particular crop. To determine the values of soil fertility indices, it is necessary to examine cultivated lands regularly. If agrochemical and agrophysical indicators of soil quality and fertility differ within the same field significantly, then the cost of assessment tools for the subsequent rational distribution of fertilizers and increase yield will pay off quickly [3, p. 68].

Traditional soil surveys carried out manually without precise reference to the terrain do not often reflect the real picture and dynamics of changes in the soil indices of cultivated lands. This may lead to incorrect results in calculating fertilizer doses. One can find a variety of designs of mechanized devices for sampling soil (self-propelled, mounted) in the implementation of modern agricultural technologies. However, they have disadvantages despite the obvious superiority over manual sampling devices. The disadvantages are: manual control and manual delivery of the car by the driver to the soil sampling point and back, multiple movements around the field that damage the soil fertility, delayed operations due to the increased travel time to the sampling point and in the case of mounted equipment - installation of the device on a traction machine, high cost, etc. [3, p. 68].

The task of creating devices for assessing the temporal and spatial heterogeneity of agricultural land (including agrochemical and agrophysical indicators of soil quality and fertility) which will be efficient and inexpensive in the production and operation is relevant in the framework of an economically and ecologically efficient concept of precision farming $[4$, p. 99].

\section{Literature Review}

Sampling during agrochemical examination of soils is carried out throughout the growing season. Samples are taken two months after fertilizing in the fields, areas of hayfields, pastures, forest nurseries, where the dose of applied fertilizers for each species was more than $90 \mathrm{~kg}$ for 1 ha.

The cartographic basis for sampling is the land use plan of the farm with the elements of on-farm land management plotted on it and the boundaries of the soil contours.

Agrochemical examination includes: determination of acidity, mobile phosphorus, metabolic potassium, organic matter, hydrolytic acidity, calcium, magnesium, degree of saturation with bases, as well as trace elements, heavy metals and radionuclides $[5,6]$.

An agrochemical survey is not possible without sampling the soil, so we reviewed existing tools for sampling. 
Cane drills or similar drills with the same metrological characteristics as BP-25-15 drills are used as hand tools, as well as bayonet shovels, linen bags, plastic or paper bags, cardboard boxes, labels and a cartographic base.

The territory intended for examination is divided into elementary sections in accordance with the grid of elementary sections. The distance between point samples is determined.

Spot samples are taken with a drill. Spot sampling with a shovel is allowed on compacted soils.

Point samples should not be taken near roads, heaps of organic and mineral fertilizers, ameliorants, from the bottom of breakup grooves, in areas that differ sharply in the best or worst condition of plants.

Point samples are taken evenly along the route course at equal intervals within each elementary site. Spot soil samples are taken on the beds between sowing rows or rows of planting seedlings in forest nurseries (in fields occupied by seedlings).

Point samples are taken to the depth of the arable layer on arable soils. On hayfields and pastures point samples are taken to the depth of the humus-accumulative horizon but not deeper than $10 \mathrm{~cm}$.

The combined sample is made up from the point samples taken from the elementary site.

If several soil contours are located within the elementary site, then the combined samples are taken from the prevailing contour.

Each combined sample is made up of 20-40 point samples depending on the variegation of the agrochemical parameters of soils identified by the results of the previous agrochemical examination.

The mass of the combined sample should be at least $400 \mathrm{~g}$.

The combined samples taken during the day are dried in opened bags or boxes in a dry, ventilated room.

An accompanying statement is made in two copies and sent for analysis after completion of sampling of the combined samples in the household. One copy of the sheet is attached to the samples. The second remains with the specialist conducting the agrochemical examination.

In agriculture, the scope of activity of robotic devices is wide. One of the types of such activity is soil sampling on farmland. This process operation is performed when creating farmland fertility maps; binding dynamics of changes in agrophysical and agrochemical indicators of a particular farmland to time and space; determining the doses and timing of fertilizing the soil, as well as solving other specific problems [7, p. 2-6].

Currently, manual methods and devices for sampling soil are replaced by automated soil intakes on a ground-based self-propelled technological tool [8, p. 163].

A device invented at the University of Namik Kemal (Turkey) is known. The machine consists of mechanics, hydraulics and electronic systems for sampling the soil. In addition, the system has a GPS module for determining the location of the soil sampling point. The developed machine was attached to the tractor using a three-point coupling system. It can take samples from a depth of $30 \mathrm{~cm}$ to a resistance of $4 \mathrm{MPa}$. It was found 
that the machine can take 40-162 g of soil sample in one turn during field tests, depending on the resistance to penetration into the soil. It was proved that the machine can be used for sampling soil as a result of field tests. In addition, sampling points are recorded using the GPS module [9, p. 1-2].

It is known design of a robotic device for sampling soil mounted on an unmanned aerial multi-rotor helicopter-type apparatus developed at the All-Russian Research Institute of Electrification of Agriculture.

Each of these tools has its own advantages and disadvantages. The integrity of the obtained soil sample can be attributed to the advantages for a hinged machine mounted on a tractor. The disadvantage is the high weight of the unit and, as a result, a significant impact on the soil during moving to the sampling site. In addition, a clear disadvantage is the high energy consumption both for sampling which is carried out by pressing a hollow cylinder into the soil and for reaching a predetermined sampling point, because the tractor does not perform any useful work.

In the case of using an aircraft for transportation and sampling of soil, the effect on the soil is minimal and the speed of reaching the specified coordinates is maximal. However, modern unmanned aerial multi-rotor helicopter-type apparatus have serious limitations on the maximum take-off weight, as well as the time and range of autonomous flight.

The soil sampling methods considered above have significant drawbacks. Therefore it is advisable to aggregate the soil sampling installation with a light autonomous robotic platform (for example, Thorvald). Having a low mass, it has a slight effect on the soil. Its battery life is up to ten hours.

During the execution of a technological process, the operator is required to continuously follow the course, managing a technical tool. The operator may stray off course due to increased tension during operation. As a result he will have to re-pass this area. The time of the operation increases in such situation. The internal structure of the soil deteriorates with repeated passage that affects the yield. In order to prevent unnecessary passages and not to harm the soil and crops during the implementation of technological processes of agriculture, it is proposed to introduce a control system for the movement of the field agro-robot.

The introduction of an autonomous motion control system will allow existing mobile robots to move automatically most of the workflow without continuous operator control [10, p. 130].

Based on the foregoing, it can be concluded that the process of sampling soil is necessary for conducting agricultural activities and requires a significant investment of time. One of the solutions to reduce the time spent on soil analysis is the use of robotic systems, which are able to collect soil samples from predetermined sites in offline mode.

\section{Materials and Methods}

An analysis of literary sources showed that there is a problem of maintaining soil fertility in agricultural production and the introduction of precision farming systems, as well as increasing the level of automation in the industry. Equipment for sampling soil, including using automation tools was studied. The work used monographic and general scientific research methods. 


\section{Results and Discussions}

To ensure sampling during agrochemical inspection of soils in an autonomous mode, it is necessary to install a sampler on a robotic platform, which will ensure sampling from a given depth without direct human involvement. Since the study of literary and Internet sources did not reveal the existence of commercially available models of samplers, we developed a working tool for the sampler to be installed on a robotic platform carrier.

The scheme of the developed working tool for the robotic complex of soil sampling is presented in Figure 1.

The sampler consists of a frame (4) supported on racks (5). A platform (3) is mounted on the frame. It is able to move freely in a vertical plane due to the rollers and guides. A controlled gearbox (2) is installed on the platform, on spacers (6). A buried unit (1) is attached to it. Its movement is limited by the latch (7) in the vertical plane.

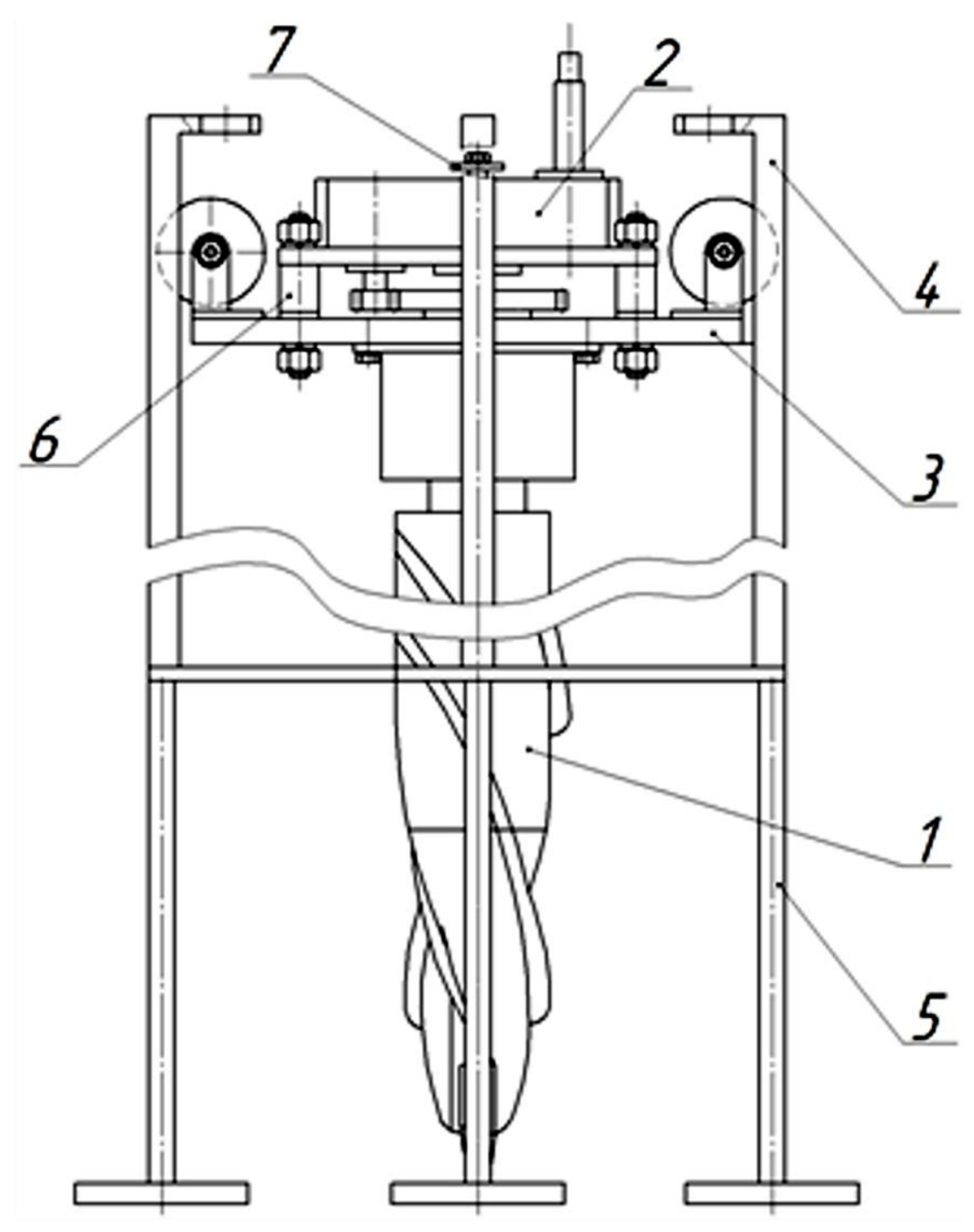

Figure 1. The scheme of the working tool for the robotic complex of soil sampling 
A buried unit was developed for penetration into the soil. The scheme of it is shown in Figure 2.

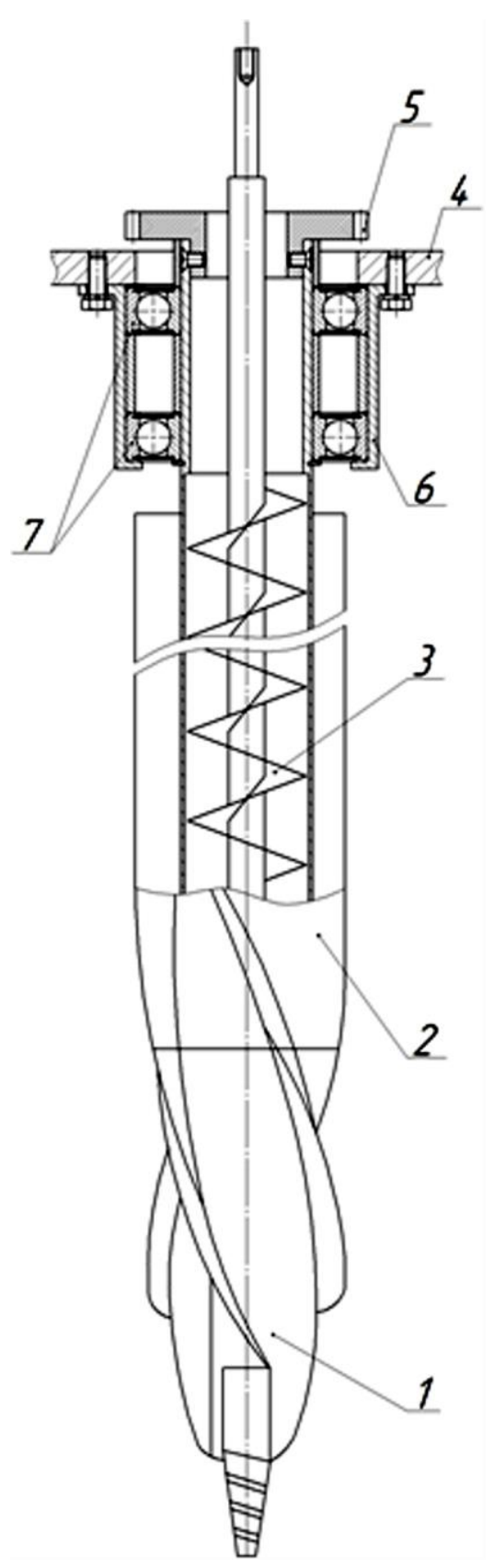

Figure 2. Scheme of the buried unit

It consists of a hollow drill 2 fixed in ball bearings 7 . The drill is attached to the mounting plate 4 of the platform with the help of a glass 6 and bolts. A screw 3 is inserted into the cavity of the drill with the drill head 1 fixed on it. Gear 5 is put on the hollow drill and fixed with screws.

After the robotic carrier platform has reached the sampling point, it lowers the sampler until it stands upright on the ground with the platform 3 moving to its highest position. 
After the positioning of the sampler is completed, the controllable gearbox switches to the burial mode. The torque from the input shaft of the gearbox is transmitted to the buried unit, which comes into rotation. Due to the geometric shape of the outer surface it begins to sink into the soil while the platform 3 is lowered after it.

Having reaching a predetermined depth, the controllable gearbox switches to sampling mode. The torque is transmitted only to the auger and the associated drill head in this mode. The drill head and auger are being recessed another 30 millimeters (the movement of the drill head is limited by lock 7) and the sampling is taken place.

The controllable gearbox switches to the mode of raising the drill at the end of the sampling process and at the same time, the robotic carrier platform initiates the lifting mechanism of the sampler. The rotation of the buried module is performed in the opposite direction from the original direction in the mode of raising the drill. As a result the buried node is removed from the soil.

At the end of the sampler lifting, the controllable gearbox is turned off and the carrier's robotic platform moves to the next point according to the route.

\section{Conclusions}

An agrochemical analysis of the soil is a prerequisite for maintaining the fertility of the land used and obtaining high yields when conducting agricultural production. Agrochemical analysis is impossible without sampling the soil. Soil sampling is performed without the use of automatic devices in many farms. This makes this operation time and resource intensive.

Various options for carrier platforms for an automatic soil sampling system are considered. As a result of the analysis, the feasibility of using a light autonomous robotic platform is substantiated.

The developed working tool for the robotic complex of soil sampling installed on a robotic platform and the use of autonomous control systems will make it possible to collect soil samples in automatic mode, which will significantly reduce the time and energy consumption for performing agrochemical control, as well as increase the level of automation.

\section{References}

(1) Nechaeva, T. V.; Bykova, S. L. The Role of Agrochemistry in the Conditions of Modern Agriculture in Russia (in Russian). Zhivyye i biokosovyye sistemy (Living and Biocos Systems) 2014, 7. https://jbks.ru/assets/files/content/2014/issue7/article7.pdf (accessed Feb 22, 2020).

(2) Badenko, V. L.; Terleev, V. V.; Latyshev, N. K.; Krylova, I. Yu.; Muravyova, L. S. Agrophysical soil research for precision agriculture technologies: Problem statement and method (in Russian). Soil Fertility 2011, 1, 29-31.

(3) Bashilov, A. M.; Korolev, V. A.; Mozhaev, Ky. Prospects for the Use of Drones in the Implementation of the Latest Agricultural Technologies (in Russian). Bulletin of AllRussian Research Institute of Electrification of Agriculture 2016, 4 (25), 67-75. 
(4) Korolev, V. A.; Bashilov, A. M.; Kozhemyakin, S. A.; Vorotnikov, S. A.; Polsky, V. A. A Complex of Operational Analysis of the State of Cultivated Land (in Russian). Alternative Energy and Ecology (ISJAEE) 2013, 7, 99-106.

(5) Obermeier, M. M.; Gnädinger, F.; Durai Raj, A. C.; Obermeier, W. A.; Schmid, C. A. O.; Balàzs, H.; Schröder, P. Under Temperate Climate, the Conversion of Grassland to Arable Land Affects Soil Nutrient Stocks and Bacteria in a Short Term. Science of The Total Environment 2020, 703, 135494. https://doi.org/10.1016/j.scitotenv.2019.135494.

(6) Silva, E. M.; Furtado, T. D. R.; Frühauf, A. C.; Muniz, J. A.; Fernandes, T. J. Bayesian Approach to the Zinc Extraction Curve of Soil with Sewage Sludge. Acta Scientiarum. Technology 2019, 42, e46893. https://doi.org/10.4025/actascitechnol.v42i1.46893.

(7) Sychev, V. G.; Afanasyev, R. A. Robotics in precision farming technologies (in Russian). Soil Fertility 2016, 3, 2-6.

(8) Korolev, V. A.; Bashilov, A. M.; Mozhaev, K. O. The Structure and Operation Algorithms of a Flying Robot for Sampling and Soil Analysis of Agricultural Land (in Russian). Alternative Energy and Ecology (ISJAEE) 2015, 13, 177-178.

(9) Dalmis, I. S.; Akdemir, B.; Turen, N.; Belliturk, K. Development of an Automatic Soil Sampling Machine. Journal of Tekirdag Agricultural Faculty 2016, 13 (3), 1-12.

(10) Egorova, M. V. Development of a system for controlling the movement of a field agro-robot (in Russian). System Administrator 2018, 7-8, 130-138.

\section{Information about Authors}

Alexey Alexandrovich LEONOV: Ph.D. in Engineering, Associate Professor, Department of Agricultural Engineering, Faculty of Engineering, Kuzbass State Agricultural Academy; 5 Markovtsev Str., Kemerovo, 650056, Russia; e-mail: tmrm@ksai.ru.

Olga Vladimirovna SANKINA: Ph.D. in Engineering, Associate Professor, Department of Agricultural Engineering, Faculty of Engineering, Kuzbass State Agricultural Academy; 5 Markovtsev Str., Kemerovo, 650056, Russia; e-mail: tmrm@ksai.ru. 